\title{
A Integração de Tecnologias Digitais e a Constituição de Metodologias Interativas e Dialógicas: desafios e possibilidades na Educação Superior
}

\author{
Marilene Alves Ramos Dias \\ Universidade Federal do Tocantins - UFTO \\ Eduardo Fofonca \\ Instituto Federal do Paraná - IFPR \\ Katia Andréa Silva da Costa \\ Universidade do Estado de Santa Catarina - UDESC
}

\begin{abstract}
Resumo
A educação contemporânea ultrapassa as fronteiras do contexto interior da sala de aula e acaba possibilitando novas dimensões, principalmente por meio da integração e convergência tecnológicas. Esse processo de integração exige aos professores novas metodologias e práticas de ensino e, para os alunos, novos desafios, saberes e habilidades para a sua formação e inclusão no mundo do trabalho. Diante disso, objetivou-se com este estudo, verificar as relações entre professor, aluno e o uso das tecnologias digitais de informação e comunicação (TDIC) na Educação Superior. O estudo, de natureza qualitativa, foi realizado por meio de uma pesquisa de campo, com observação direta extensiva e a aplicação de um questionário composto por perguntas fechadas e de múltiplas escolhas aplicado a professores da Universidade Federal do Tocantins, campus de Gurupi. Observou-se, com a aplicação da pesquisa por meio do questionário, a importância do uso de diferentes tecnologias e metodologias, considerando alguns modelos de êxito no desenvolvimento de uma educação mediada por tecnologias de forma mais interativa e dialógica, considerando, sobretudo os diferentes estilos de aprendizagem.
\end{abstract}

Palavras chaves: Tecnologias digitais de informação e comunicação; Metodologias; Educação superior.

\begin{abstract}
Contemporary education goes beyond the boundaries of the inner context of the classroom and ends up allowing new dimensions, mainly through technology integration and convergence. This integration process requires new teaching methodologies and practices for teachers, and, for students, new challenges, knowledge, and skills for their training and inclusion in the world of work. Therefore, the purpose of this study was to verify the relationship between teacher, student and the use of digital information and communication technologies (TDIC) in Higher Education. The qualitative study was carried out through field research, with extensive direct observation and the application of a questionnaire composed of closed questions and multiple choice questions applied to professors at the Federal University of Tocantins, Gurupi campus. The
\end{abstract}


application of the questionnaire survey showed the importance of the use of different technologies and methodologies, considering some models of success in the development of a technology-mediated education that is more interactive and dialogical, taking into account, in particular, the different styles of learning.

Keywords: Digital information and communication technologies; Methodologies; College education.

\section{INTRODUÇÃO}

$\mathrm{Na}$ contemporaneidade, a educação ultrapassa as fronteiras do contexto interior da sala de aula e acaba por possibilitar novas dimensões, especialmente por meio da integração e convergência digital das tecnologias da informação e comunicação. Pode-se considerar, neste contexto, que estas dimensões exigem e desafiam os professores com novas metodologias e práticas de ensino cotidianamente, mas também possuem repercussões na vida acadêmica e social dos estudantes, tendo em vista que os mesmos são desafiados por novas formas de se fazer pesquisa e, sobretudo, estão cada vez mais imersivos em contextos de aprendizagem que se estabelecem por meio das múltiplas relações em que as tecnologias digitais são um meio tangível de construção de conhecimento.

Desse modo, este artigo tem como objetivo verificar as relações entre professor, aluno e o uso das tecnologias digitais de informação e comunicação (TDIC) no contexto educacional, apresentando dimensões metodológicas e tecnológicas, tratando não somente da seleção de técnicas, procedimentos e dos recursos didáticos a serem utilizados no contexto da sala aula, mas também da relação, articulação, estruturação e a combinação que estes elementos terão.

De acordo com Fofonca (2014), as relações que são estabelecidas contemporaneamente entre a cultura digital e a educação criam novas condições e inúmeras estratégias para integrar de maneira eficaz as tecnologias digitais da informação e da comunicação. Essas mudanças repercutem na sociedade e na ação educacional, com novas possibilidades de se observar os processos de ensino e aprendizagem, levando ao ensino de qualidade. Quando o assunto em discussão envolve tecnologias digitais da informação e da comunicação (TDIC), gera a necessidade dos profissionais da área educacional adquirirem novas potencialidades para utilizá-las adequadamente, perante mudança na organização do processo de ensino, o que significa criar mecanismos para se apropriar delas com 
planejamento e integrá-las aos objetivos. Portanto, torna-se de suma importância verificar níveis de integração por meio das respostas obtidas através dos questionários, nos quais discutem sobre os recursos tecnológicos e de que maneira sua integração pode contribuir ou não para os processos de ensino e aprendizagem.

Desse modo, torna-se interessante ressaltar que o próprio caminho que a sociedade está tomando, no que se refere às tecnologias digitais, acaba por exigir uma revisão de concepções, metodologias e recursos na área da Educação. Parafraseando Areu e Fofonca (2014), estar diante desse processo de mudança e reflexão acerca da integração das tecnologias acaba por corroborar para discussões importantes em torno da ampliação das relações entre tecnologia, cultura digital e educação.

Assim, torna-se necessário a qualificação do professor, para que este possa levar os alunos à construção do conhecimento, pois, como diz Fofonca (2012, p.88), "o importante diante do fato da inserção ou integração das tecnologias é não pensar, assim como em outras épocas, que somente por meio da tecnologia que teremos avanços e melhoria na qualidade da educação". Os recursos tecnológicos não ensinam sozinhos, é importante que o professor esteja preparado para utilizá-los com seus alunos para que o uso de recursos e das estratégias didáticas promova a aprendizagem. Assim, "a presença de uma determinada tecnologia pode induzir profundas mudanças na maneira de organizar o ensino" (KENSKI, 2012, p. 44). Uma vez que as tecnologias promovem mediações entre as abordagens do professor (conhecimento) e a compreensão do aluno junto aos procedimentos pedagógicos (aprendizagem), pode-se dizer que ambos os processos devem estar estruturados e adequados ao esperado no processo educacional, considerando, sobretudo, os objetivos propostos pelo professor em seu planejamento didático-metodológico.

Desse modo, há a necessidade de um debate aprofundado acercado uso das tecnologias digitais da informação e da comunicação no contexto educacional, e, portanto, esta pesquisa de natureza qualitativa descritiva, apresenta-se por meio da técnica de amostragem probabilística aleatória simples, com pesquisa de campo aplicada através de observação direta extensiva, com a aplicação de um questionário para professores da Universidade Federal do Tocantins, mais especificamente no campus de Gurupi. Ainda tornase relevante destacar que o questionário foi composto por perguntas fechadas e de múltiplas 
escolhas com o objetivo de uma compreensão mais aprofundada das concepções trazidas nos questionamento e, portanto, para corroborar uma análise de dados mais fidedigna.

\title{
A INTEGRAÇÃO DAS TECNOLOGIAS DIGITAIS NA EDUCAÇÃO
}

\begin{abstract}
Muitas pessoas falam sobre a integração das tecnologias, porém poucos professores sabem exatamente como proceder. $O$ fato é que a integração de fato exige mudança [...] Todavia, o que parece que falta é um modelo, o qual os professores possam usar para guiá-los diante das mudanças necessárias que precisarão fazer para conseguirem integrar as novas tecnologias com sucesso em sala de aula (WOODBRIDGE, 2004, p. 1).
\end{abstract}

A sociedade contemporânea vive os desdobramentos e a dinâmica dos efeitos tecnológicos em sua plenitude. Pode-se dizer que atualmente os modelos de ensino e o uso de algumas tecnologias deve-se à própria a ação mediadora desenvolvida pelo professor no momento de seu planejamento, produção, pesquisa para a concretização de sua aula. No entanto, torna-se relevante destacar que muitos deles, em sua formação inicial, não tiveram qualquer disciplina curricular sobre o processo de integração de mídias e tecnologias digitais em seu trabalho. No entanto, nesse sentido, o contexto da escola e a própria sociedade exige que os professores saibam utilizar as tecnologias digitais em sua prática pedagógica, contudo observa-se que existem fatores limitantes para que esse processo ocorra, tais como: falta de recursos na escola, desinteresse por uma pedagogia mais inovadora, falta de apoio da equipe pedagógica ou, até mesmo, o desconhecimento do uso das ferramentas por parte dos docentes.

Assim, contextualmente, a escola nessa nova era tecnológica necessita de um sistema educacional reformulado, no qual se agreguem novos saberes, os quais, muitas vezes, são trazidos pelo próprio mundo discente ao cotidiano escolar. Nesta perspectiva, os atores da escola e a própria escola devem ter uma revisão clara de sua filosofia enquanto espaço de construção de conhecimento, reconhecendo que a aprendizagem precisa reconhecer as várias faces do ensino, principalmente aquelas que se concretizam através de leituras atentas de uma pedagogia social, isto é, lendo a realidade em que seu aluno está imerso e do qual ele faz parte. Com o objetivo de refletir sobre a formação de professores a as mudanças nos métodos de ensino, Fofonca (2011) destaca que:

Estes saberes remetem-nos a uma reflexão sobre os métodos de ensino, tendo em vista que os docentes, por dogmatismo, não despertam a curiosidade ou o espírito crítico dos seus alunos, em vez de desenvolvê-los. Mais ainda, a educação formal 
brasileira tende a privilegiar o acesso ao conhecimento, em detrimento de outras formas de saberes e de aprendizagens, o que nos direciona na contemporaneidade a uma educação que contemple os meios de comunicação como métodos, caminhos à aprendizagem, explicitamente modernos e eficazes (FOFONCA, 2011, p.9).

Nesse sentido, as tecnologias digitais podem ser uma forte conexão entre os novos saberes e as práticas educacionais, facilitando o acesso ao conhecimento e integrando tais tecnologias como apoio e suporte ao ensino, estimulando um encontro profícuo entre a educação e a tecnologia. Contudo, Demo (2008) afirma que, devido o constante e célere desenvolvimento das inovações tecnológicas, surgem adventos no modo de viver e produzir que nos lançam novos desafios cotidianamente. Portanto, as mudanças ocorridas hodiernamente na sociedade exigem uma nova postura por parte do professor em sala de aula, haja vista que o profissional docente da contemporaneidade necessita estar harmonizado com o locus social no qual se insere em prol de um ensino mais eficaz e eficiente. Além disso, o uso adequado das tecnologias digitais se apresenta como uma alternativa para possíveis mudanças atitudinais nas práticas de ensino. Desse modo, cabe ao professor ampliar esse rol de recursos, métodos e linguagens disponíveis, explorando e mediando o conhecimento de múltiplas formas a fim de oportunizar ao aluno novas possibilidades de ensino. Coadunando com este pensamento, Demo (2008) destaca que:

Embora haja muita fantasia e retórica em torno em torno da virada do milênio, o que existe de mais concreto é o advento de modos de viver e produzir que nos lançam novos desafios, exacerbados, entre outras coisas, pela pressa das inovações tecnológicas (DEMO, 2008, p.5).

Diante desse contexto, Beard (2008) mostra que as evidencias comprovam que investir em formação de professores é um investimento produtivo para aumentar a eficácia e a melhoria na escola. Os professores precisam acompanhar as mudanças sem refutar o uso das novas tecnologias e da formação continuada. É de suma importância para o professor buscar o seu aperfeiçoamento contínuo, adotando novas metodologias que surgem para auxiliar os processos de ensino e aprendizagem adotados. Dessa forma, é necessário que o educador esteja atento às transformações, sempre objetivando buscar o conhecimento e percebendo os anseios dos seus alunos. Nesse sentido, Kenski (2007) enfatiza:

Portanto, não basta assimilar informática, internet e outras tecnologias do conhecimento; as novas tecnologias trazem transformações nas formas de trabalhar o conhecimento exigindo e trazendo, por sua vez, novas formas de trabalhar o conhecimento e exigindo novas formas de organização do tempo, do espaço, das relações internas da escola (KENSKI, 2007, p. 46). 
Estas considerações mostram que todos os profissionais se beneficiam quando participam da formação e da mediação do professor com o uso de recursos tecnológicos, refletindo diretamente na qualidade do ensino. Neste sentido, Oesterreich (2010) diz que a qualidade dos recursos tecnológicos quanto à facilidade de utilização, conteúdo didático e acessibilidade são pontos que devem ser considerados com especial atenção, pois são exatamente esses recursos que permitirão ao aluno visualizar, participar, interagir, cooperar e construir o conhecimento.

O desafio da contemporaneidade refere-se, principalmente, à adequação do processo de ensino e aprendizagem convencional às inovações tecnológicas, introduzindo metodologias mais inovadoras como objetos de aprendizagem. Diante da relevância das tecnologias digitais da informação e da comunicação no aprendizado dos indivíduos, o próprio governo vem fomentando a utilização de TDIC nas universidades visando implementar a construção do conhecimento com essas ferramentas digitais. Há, portanto, um olhar potencial sobre os impactos das TDIC na educação, sobretudo quando se criam expectativas dos processos de mudança com novos cenários, espaços e a necessidade de rever as metodologias aplicadas ao ensino, que relativamente são inerentes à melhoria da qualidade dos processos de ensino e de aprendizagem. Os argumentos a favor da incorporação das tecnologias nos processos de ensino tornaram-se muito discutidos na atualidade, no entanto não podem e não devem ser ratificados tendo em vista as possíveis facilidades que essas tecnologias oferecem na implementação de certas metodologias de ensino ou certos posicionamentos pedagógicos, uma vez que se não bem usada, a tecnologia digital aplicada à educação pode assumir efeito negativo na práxis didático-pedagógica.

Em linhas gerais, todo o campo de desenvolvimento dos cenários de integração das tecnologias, parafraseando Coll, Mauri e Onrubia (2010) ocorreram primeiramente a partir da incorporação dos computadores nas escolas; depois com a incorporação da internet; e, agora, está acontecendo com o software social e com as ferramentas e aplicativos da web. Porém, quais são as implicações compreendidas acerca das mudanças apresentadas no campo da educação com a integração das tecnologias?

De acordo com Coll et al (2010) as implicações dessa mudança de perspectivas são claras. Para os autores, por um lado, o interesse se desloca para a análise das potencialidades das tecnologias no ensino e na aprendizagem para o estudo empírico dos usos efetivos que 
professores e alunos fazem destas tecnologias no transcurso das atividades de ensino e aprendizagem. Por outro lado, "as possíveis melhoras de aprendizagem dos alunos são vinculadas à sua participação e envolvimento nessas atividades, nas quais a utilização das TDIC é um aspecto importante, mas apenas um entre os muitos aspectos relevantes envolvidos" (COLL; MAURI; ONRUBIA, 2010, p.70).

Desta forma, Fofonca (2015) esclarece que o argumento fundamental para a continuidade num nível de desenvolvimento e crescimento de absorção dos campos sociais, como a educação e as potencialidades exploradas das TDIC educacionalmente, mesmo com alguns limites, está em verificar que o real potencial atribuído à mudança não está somente na disponibilização dos recursos tecnológicos nas organizações de ensino, mas deve ser percebido como uma concepção metodológica, que compreenda a integração curricular efetiva deste processo.

\section{O CONTEXTO E CAMINHOS DA PESQUISA}

No que se refere ao contexto e aos caminhos da pesquisa, inicialmente serão apresentados os sujeitos e as instituições corpora da pesquisa, para, em seguida, o aprofundamento da fundamentação teórica, dos instrumentos metodológicos e da apresentação e discussão dos resultados. A pesquisa tem caráter qualitativo-descritivo, realizada por meio da investigação com profissionais da Universidade Federal do Tocantins, campus de Gurupi, com o objetivo de verificar a partir de um questionário o uso de tecnologias em sala de aula e a mediação entre as tecnologias e o ensino. Contudo, torna-se

importante destacar que o questionário foi composto por perguntas fechadas e de múltiplas escolhas, e houve a necessidade de um contato mais direto com os sujeitos investigados na pesquisa, de modo que as dúvidas com relação às questões e aos objetivos da pesquisa pudessem ser melhor esclarecidos.

Segundo Marconi e Lakatos (1999), a pesquisa de campo é utilizada com o objetivo de elucidar informações e conhecimentos acerca de um problema para qual se procura respostas. Neste sentido, as autoras destacam que este tipo de pesquisa "consiste na observação de fatos e fenômenos tal como ocorrem espontaneamente, na coleta de dados a eles referentes e no registro de variáveis que se presumem relevantes, para analisá-los" 
(MARCONI; LAKATOS, 1999, p.185). Para tanto, a construção desta pesquisa foi subsidiada através de levantamento bibliográfico com diferentes fontes, de forma a examinar a tecnologia e a educação, o computador na educação, o projeto TV Multimídia e a capacitação dos professores para a utilização das tecnologias digitais.

Concordando com Balão (2016), assume-se que o questionário seja um instrumento de coleta de dados, constituído por uma série ordenada de perguntas a serem respondidas pelo informante. Dentre as formas possíveis de formulação de questionários, escolheu-se a técnica de amostragem probabilística aleatória simples para ser aplicada aos professores que atuam no ensino superior nas modalidades presencial e semipresencial (EaD) na Universidade Federal do Tocantins. Os sujeitos investigados foram selecionados aleatoriamente conforme sua disponibilidade de tempo e seu consentimento em participar da pesquisa, e o questionário foi aplicado durante o mês de maio e junho de 2016. No entanto, registrou-se que, com a intenção de sanar dúvidas e ter maior precisão nos resultados, dois professores dentre os sujeitos entrevistados solicitaram levar os questionários para suas casas e não responderam às perguntas na hora de aplicação da pesquisa, e, desses dois, apenas um devolveu respondido o questionário que havia levado consigo. Em média, os demais professores entrevistados levaram tempo médio de quinze minutos para responder um formulário com nove perguntas fechadas. Os resultados da pesquisa foram originados das respostas dos professores e organizados em categorias percentuais. A identidade dos participantes da pesquisa foi resguardada.

\section{ANÁLISE DOS DADOS: UTILIZAÇÃO DE TECNOLOGIAS NA EDUCAÇÃO SUPERIOR DA UFT}

O primeiro aspecto verificado foi a escolaridade/grau de instrução dos sujeitos respondentes, dos quais obteve-se o seguinte resultado: 


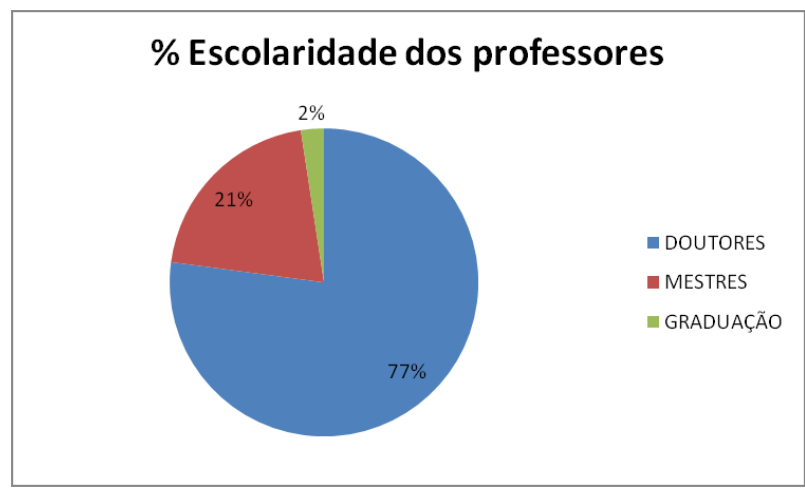

Gráfico 1- Referente à escolaridade dos professores Fonte: Pesquisa dos autores

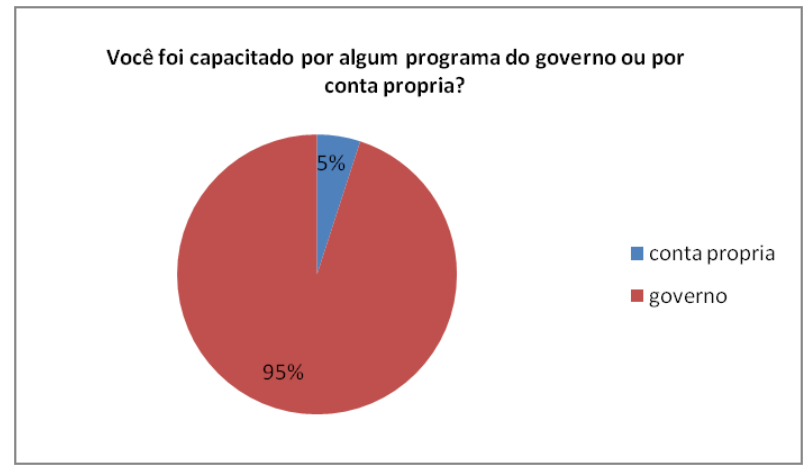

Gráfico 2 - Referente à capacitação dos professores Fonte: Pesquisa dos autores

De acordo com o resultado dos questionários aplicados aos professores, percebeu-se que a maioria tem especialização na área de atuação conforme os gráficos1 e 2 acima. Destes dois gráficos, verificou-se que $77 \%$ são doutores, $21 \%$ são mestres e apenas 2\% são graduados. Dentre as pessoas desse público, 95\% foram capacitados pelo governo e apenas $5 \%$ se capacitaram por iniciativa própria. Isso significa que num ambiente estrutural no qual há fomento governamental para políticas educacionais que incentivem o uso de tecnologias digitais na escola por meio da capacitação inicial e continuada de professores dentro da cultura escolar, os professores universitários com alto grau instrucional e acadêmico que, em sua maioria são formados no e pelo ambiente estrutural promovido por essas políticas de governo, deveriam assumir as TDIC como forma de metodologia ativa de ensino e aprendizagem, uma vez que esses professores são produtos dessas políticas educacionais. O alto grau de instrução acadêmica observado no público participante da pesquisa demonstra 
que, apesar de altamente especializados em suas áreas específicas de atuação (que são áreas diversas dos estudos sobre teorias e concepções didático-pedagógicas), os docentes apresentam boa aceitação ao uso de novas tecnologias na sala de aula (Gráfico 3). Nesse aspecto, Amaral (2008) pontua que:

E para que o professor possa se adaptar aos novos estilos de aprendizagem e, em consequência, aos estudantes da atualidade, é preciso que sua formação se modifique. Não podemos ter uma modificação no processo de ensino-aprendizagem sem que haja uma reestruturação dos cursos de formação de professores (AMARAL,2008 p. 4).

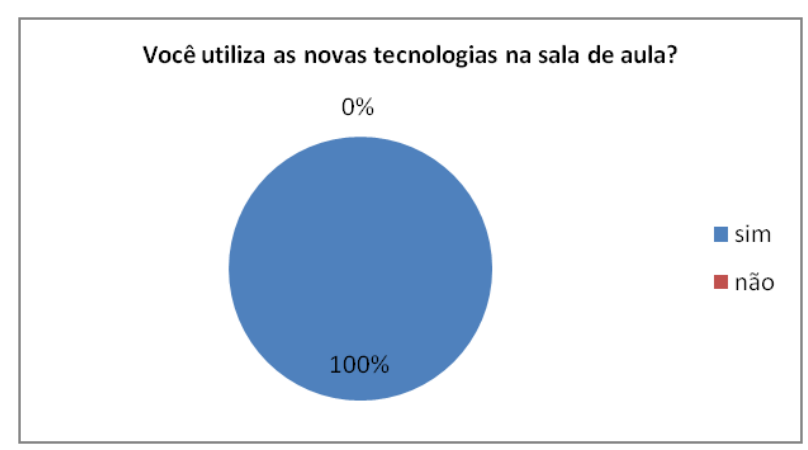

Gráfico 3- Referente à utilização das novas tecnologias na sala de aula Fonte: Pesquisa dos autores

Observou-se que $100 \%$ dos professores fazem uso das tecnologias no contexto escolar, conforme mostra o gráfico supramencionado. Para Alonso (2008), no entanto, investimentos apenas em tecnologias educacionais não dão conta de modificar o cotidiano da sala de aula e, muito menos, de potencializar a zona de desenvolvimento proximal que se cria na interação entre professores-alunos, alunos, alunos-objetos de conhecimento. Nesse aspecto, concorda-se com Vygotsky (1984, p. 97) quanto ao conceito de que a zona de desenvolvimento proximal "define aquelas funções que ainda não amadureceram, mas que estão em processo de maturação, funções que amadurecerão, mas que estão, presentemente, em estado embrionário". Para que esta aproximação ocorra, torna-se necessário que os professores façam uso, por exemplo, de softwares educacionais com laboratórios virtuais, ambientes virtuais de aprendizagem e chats, entre as outras formas possíveis de interação e integração entre tecnologia-educação-professor-aluno, proporcionando aos atores da práxis didático-pedagógica - educador e educando - a interação educomunicativa em tempo real. 
Segundo Amaral (2008), a integração da tecnologia não consiste simplesmente em acelerar o processo de aprendizagem ou ensinar novas habilidades tecnológicas se não houver a integração da utilização de recursos tecnológicos com outros esforços dentro do espaço escolar, pois segundo o mesmo autor, "é importante que o professor crie um ambiente em sala de aula que favoreça o aprendizado" (AMARAL, 2008, p.5). Assim, percebe-se que a realidade depende daquele que a vê ou a descreve, sendo necessário, portanto, termos uma visão ampla em todas as áreas do ensino, tendo consciência da importância da capacitação profissional docente que atua em todos os níveis educacionais previstos na organização estrutural do país.

Outro aspecto levantado pela pesquisa refere-se à facilitação de comunicação entre o professor e o aluno como o uso de novas tecnologias dentro do ambiente escolar. Como mostra o gráfico seguinte, $97 \%$ dos professores apontam positivamente para essa hipótese, enquanto $3 \%$ afirmam que a facilitação pode ocorrer, mas com fatores condicionantes no contexto de uso das tecnologias.

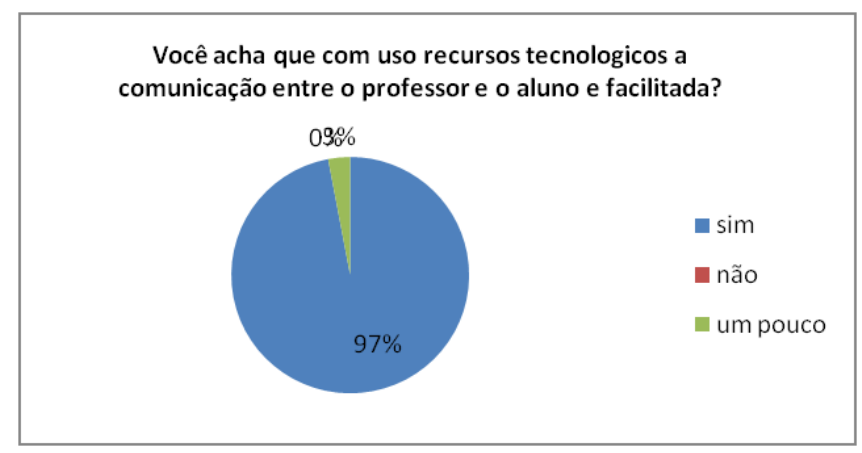

Gráfico 4 - Com o uso de recursos tecnológicos a comunicação entre professor e aluno é facilitada? Fonte: Pesquisa dos autores

O uso de giz, o quadro negro, o caderno e os livros há muito não são mais as únicas ferramentas utilizadas em sala de aula. Assim, a tecnologia tem incrementado a carreira de muitos profissionais, inclusive a do docente. Nesse viés, a pesquisa averiguou que o uso da TV multimídia em sala de aula não é habitual, sendo utilizada "às vezes - pontualmente" pela maioria maciça dos entrevistados: 97 \% (gráfico 5). Interessante notar que da totalidade, apenas 3\% dos professores admitiram nunca utilizar esse tipo de recurso tecnológico. Não houve nenhuma resposta que apontasse para a assunção da TV multimídia como recurso tecnológico utilizado com frequência. A utilização desse recurso facilita algumas 
possibilidades didático-pedagógicas referentes ao processo de ensino e aprendizagem, podendo ser encarada, inclusive, como uma alternativa metodológica para transformar o ambiente escolar universitário em um espaço mais dialógico e participativo, ao se configurar como uma integração entre as mídias mais antigas e as mais recentes. No entanto, há de se ponderar que apesar de todos os recursos da TV Multimídia, esse tipo de recurso pode não conseguir resolver o problema que limita a utilização das TIC's nas escolas: a escassez de software de boa qualidade técnica e pedagógica (MORAIS, 2006) é fator extremamente necessário para compreensão do micromundo.

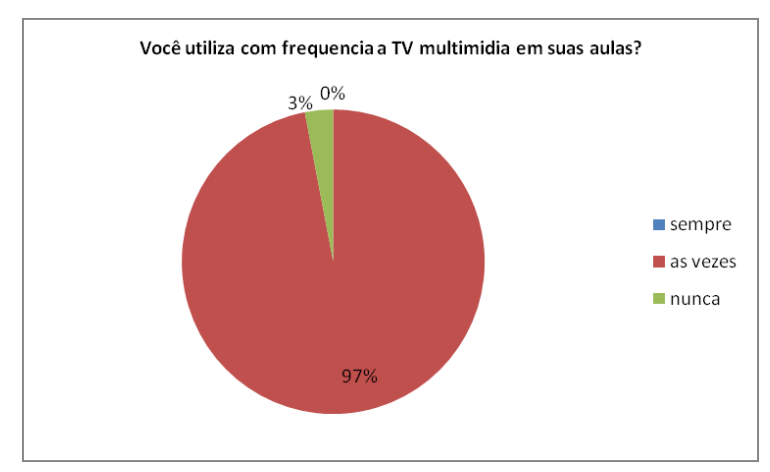

Gráfico 5- Referente à frequência de utilização da TV multimídia em aula Fonte: Pesquisa dos autores

Conforme se observa no gráfico 6, a importância do uso das tecnologias no método de ensino é assumida por $97 \%$ dos professores entrevistados, e da totalidade, apenas 3\% dos professores acreditam que a utilização de TDIC em sala de aula não influenciaria de forma significativa sua aula. Sabe-se que o uso destas tecnologias incluso no método de ensino possibilita o aluno a criar e a interagir na produção de seu próprio conhecimento, de forma a ser ativo em seu processo de aprendizagem. Os entrevistados que não consideram as TDIC relevantes para sua prática pedagógica alegam que muitos jovens não sabem usar esse tipo de recurso tecnológico na hora oportuna e da forma adequada. Nesse mote, pode-se depreender que a esses professores seria necessária capacitação para a correta utilização e integração das TDIC ao seu ambiente escolar. 


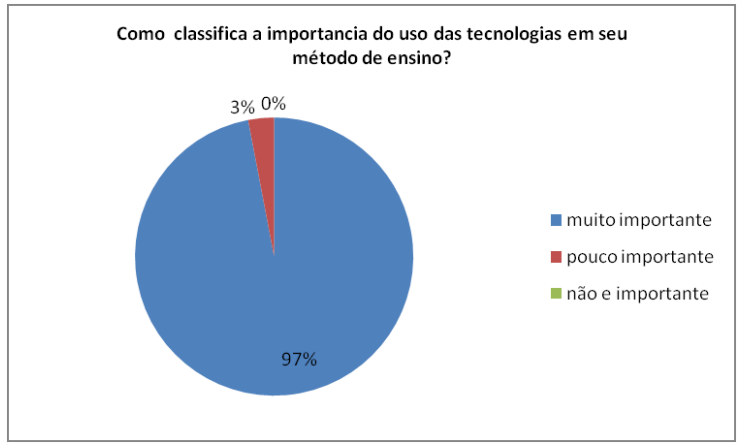

Gráfico 6- Referente à importância do uso das tecnologias no método de ensino Fonte: Pesquisa dos autores

Em relação à utilização de TDIC no ambiente/contexto do ensino a distância, o gráfico 7 demonstra que $77 \%$ dos entrevistados se consideram experientes, enquanto $23 \%$ se consideram pouco experientes ou inexperientes. Concordando com Fofonca (2010, p.19), assume-se que "Educar por intermédio de veículos de comunicação não é novidade, mas as tecnologias da comunicação e da informação, que propiciam a convergência de meios e uma comunicação bilateral, trazem à luz novas formas de educação e um novo papel educativo para os mais variados sistemas de comunicação". Acredita-se que as conveniências educativas que as diferentes tecnologias revelam no cenário da EaD oportunizadas pela implementação de vários programas de capacitação profissional estimulados por políticas de governo, entre estes a de capacitação docente, pode explicar o fato de a ampla maioria dos professores já terem tido experiência com essa vertente de ensino baseado em ambientes virtuais de aprendizagem.

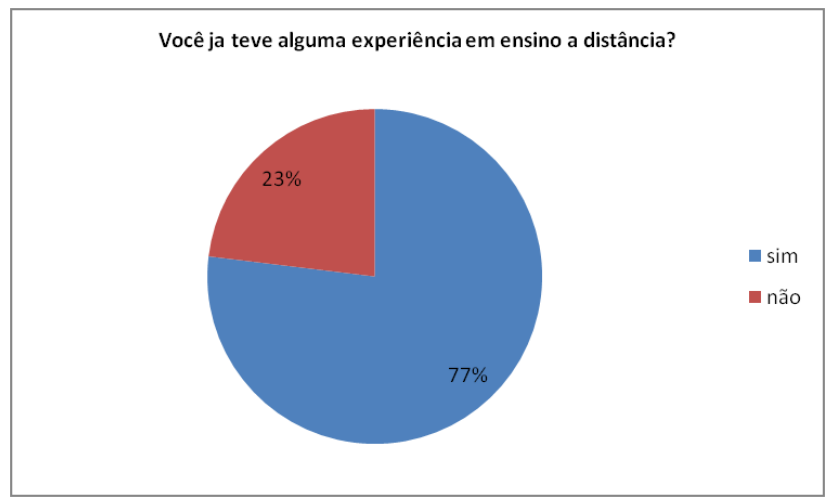

Gráfico 7- Referente à experiência em ensino a distancia Fonte: Pesquisa dos autores 
No que se refere ao uso individual dos recursos tecnológicos, conforme mostra no questionário, seguem abaixo os gráficos 8 e 9, com resultados bastante interessantes. Os recursos tecnológicos que mais se sobressaíram com 100\% de participação dos educadores foram o editor de texto "Word", editor de tabelas "Excel" e o aplicativo de apresentação multimídia "Powerpoint", seguido de 90\% de utilização da internet (acesso a Word Wide Web), 80\% de aplicativos de comunicação síncrona como "WhatsApp" e similares, 70\% de aplicativos gráficos como "Powerpoint" e "Corel Draw". Os demais recursos - ambientes virtuais de aprendizagem, filmes, músicas, vídeos e outros - apresentam menos de $50 \%$ de participação, como mostra o gráfico 8 .

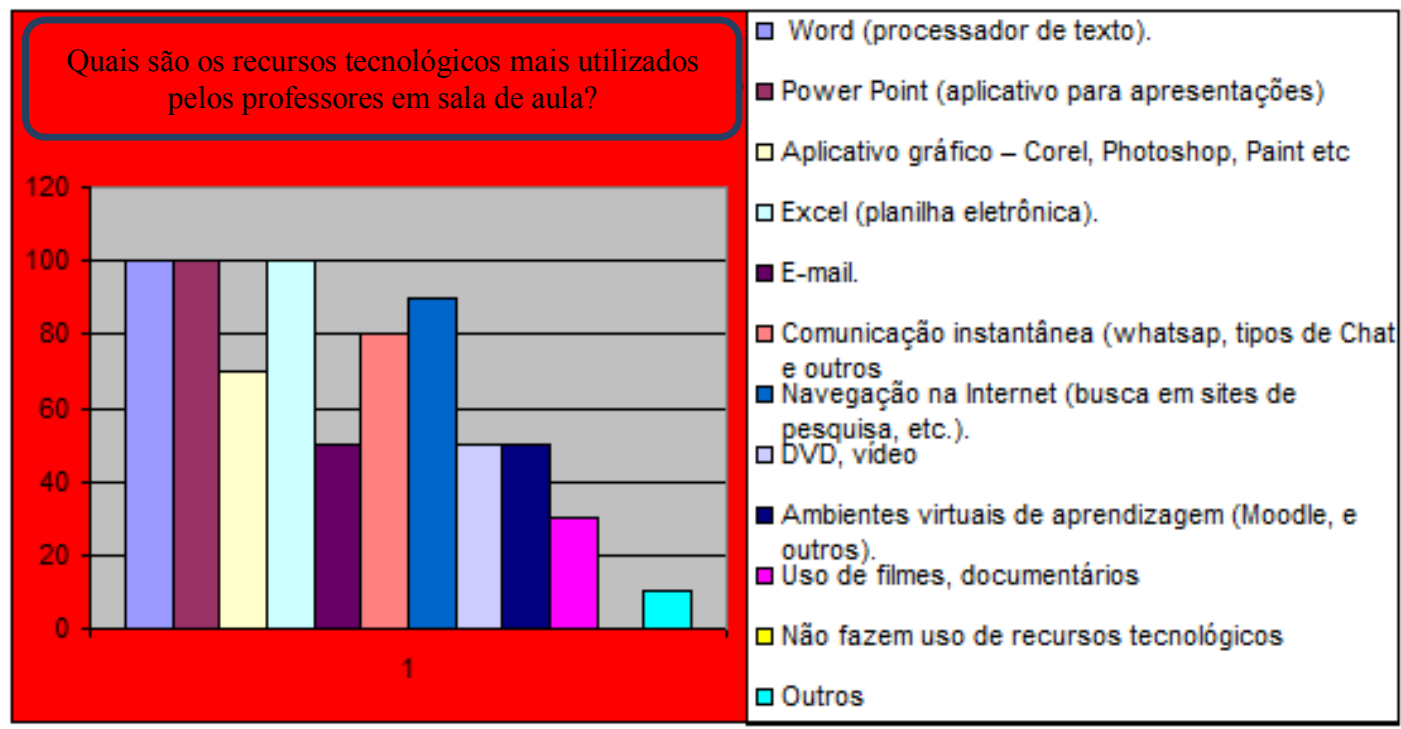

Gráfico 8- Referente a recursos tecnológicos mais utilizados pelos professores Fonte: Pesquisa dos autores

Para (Kenski, 2012, p.77 apud Fofonca, 2012, p.93) é necessário que, entre outras decisões, sejam identificadas entre as tecnologias disponíveis, as que melhor se enquadrem às propostas educativas da unidade escolar. Ou seja, as TDIC são potencialidade, mas elas por si só não garantem o desenvolvimento do processo de ensino e aprendizagem se não forem utilizadas como parte de uma reconfiguração da cultura escolar - relação entre a escola e a comunidade atendida, assim como a relação entre o professor e o aluno. Nesse sentido, apresenta-se o gráfico 9, no qual são elencados os apontamentos sobre o uso de estratégias didáticas diversificadas pelos professores entrevistados. Dentre essas estratégias, $100 \%$ dos professores realizam aulas expositivas dialogadas, $85 \%$ têm atividades orientadas em 
laboratórios, $80 \%$ tem pesquisas orientadas, 70\% aplicam seminários, 50\% fazem visitas monitoradas e 30\% realizam leituras em sala de aula. As demais estratégias pedagógicas são inferiores a $10 \%$, dentre as quais o uso de produção de mídia representa menos que 5\%, cuja alegação de falta de equipamentos disponíveis e de qualidade para a produção de mídia e/ou a preferência por métodos tradicionais de aula são o motivo para a não utilização desse recurso tecnológico. Além disso, é importante notar que os mapas mentais, apesar de didáticos, são poucos explorados, configurando o uso por apenas $10 \%$ dos sujeitos entrevistados.

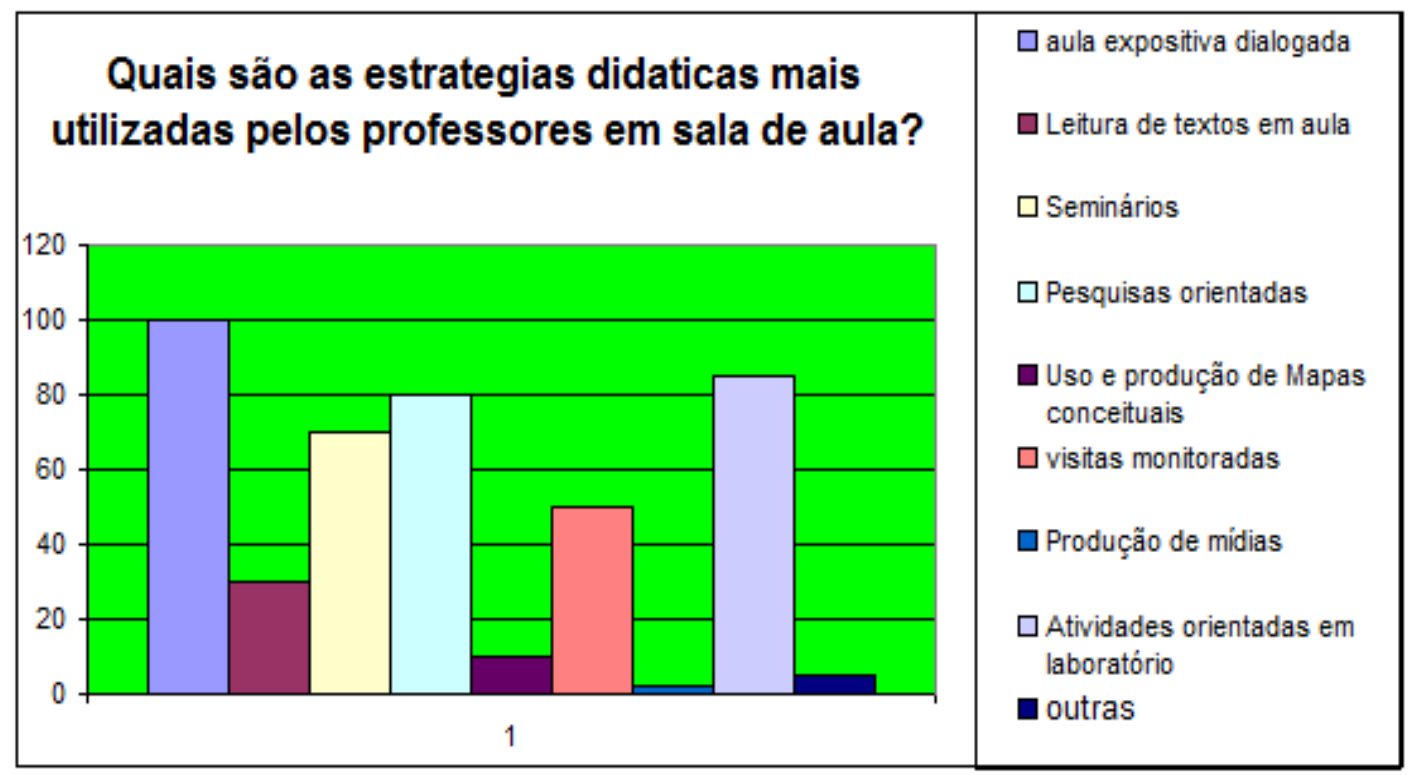

Gráfico 9- Referente estratégias didáticas mais utilizadas pelos professores Fonte: Pesquisa dos autores

\section{CONSIDERAÇÕES FINAIS}

Ao longo do desenvolvimento da pesquisa, considerou-se que no aspecto sociocultural, e, portanto, tecnológico, as transformações ocorrem em velocidade vertiginosa, cabendo ao profissional, inclusive ao profissional docente, acompanhar essas mudanças. Apesar de ser fácil essa conclusão, as dificuldades percebidas ao longo dessa investigação apontam justamente para o fato de os recursos tecnológicos digitais não serem utilizados ou serem subutilizados no ambiente escolar por falta de adequação do professor aos novos tempos da era tecnológica. Alonso $(2008$, p.750) concorda que "mais que as limitações do uso dos equipamentos, bem como da apropriação das TIC pelas escolas, há questão de fundo que 
determina a incorporação deles/as pelos alunos e professores", isto é, se as TDIC forem utilizadas adequadamente, podem ser exploradas nas várias áreas do conhecimento para atender às necessidades educacionais inter/pluridisciplinares próprias da práxis metodológica de ensino e aprendizagem. Salienta-se, entretanto, a evidência que o professor tem buscado, pouco a pouco, dominar tais tecnologias. Os professores têm demonstrado, sobretudo, conhecimento sobre os recursos tecnológicos hoje disponibilizados nas escolas, inclusive, reconhecendo a importância de sua aplicação no contexto metodológico de suas aulas.

A potencial e significativa mudança que as TDIC podem trazer para o processo de ensino e aprendizagem, bem como a capacidade de impulsionar o professor a buscar novos conhecimentos e se adequar às constantes mudanças que a sociedade nos dias atuais em termos tecnológicos é impressionante. A perspectiva de ensino mediatizada pelos recursos tecnológicos oportuniza o docente a se libertar dos métodos da educação tradicional, cuja figura docente era a detentora máxima do saber e a figura do aluno era receptáculo vazio de informações, numa relação vertical de professor para o aluno. Com uma nova sociedade mediatizada pelos recursos tecnológicos inovadores e na qual as informações estão ao alcance de qualquer sujeito que tenha acesso à internet e a um aparelho que possa acessar seu conteúdo, é possível assumir uma nova postura dentro da cultura escolar, na qual o aluno e o professor assumam funções ativas na construção de conhecimento, trabalhando os conteúdos da educação formal com a integração tecnológica conjeturada como metodologia inovadora de ensino e aprendizagem. Nessa concepção, a construção do conhecimento é conjunta, horizontal e se dá pela mediação das informações que podem ser disponibilizadas, inclusive, pelas TDIC, constituindo-se num leque de oportunidades educativas que as diferentes tecnologias revelam, cabendo ao professor adequá-las às necessidades da escola e do aluno.

Durante o período de aplicação do questionário na pesquisa de campo com os professores, pode-se notar, através das observações, que existe necessidade de um olhar mais voltado à metodologia de ensino, principalmente com a crescente aplicação de tecnologias nos processos de ensino e aprendizagem. Isto porque, embora $80 \%$ dos professores utilizem as TDIC em suas aulas, muitas deles não se sentem preparados para integrar o uso de recursos tecnológicos em seu cotidiano e os subutilizam como meros acessórios tecnológicos, não aproveitando a sua capacidade pedagógica na totalidade. Nessa investigação, notou-se, através dos dados, que mesmo no ensino superior, os professores que têm mais acesso às inovações 
tecnológicas em amplo sentido, inclusive às novas concepções metodológico-pedagógicas aplicadas ao ensino, não conseguem absorver essas percepções para aplicá-las em sala de aula com seus aprendizes.

Dessa forma, depreende-se haver um possível hiato entre o discurso de aplicar as tecnologias na educação, veiculado pelas políticas de governo aplicadas à educação formal, e a prática efetiva dessa ação. A utilização das TDIC como recursos tecnológicos integrados ao ambiente escolar e parte da práxis didático-pedagógica da sala de aula, comparadas à prática de aplicação de TDIC nos processos educacionais visualizados no caso em tela, é superficial em comparação à potência que esses meios podem atingir se assumidos e digeridos pelo profissional docente como metodologia ativa de ensino e aprendizagem, e não apenas como mero recurso tecnológico.

Afinal, o que se reflete nessa pesquisa é que o profissional docente deve ter a oportunidade de discutir como se aprende e como se ensina com as TDIC e deve também ter a chance compreender a própria prática e de transformá-la.

\section{REFERÊNCIAS}

ALONSO, K.M. Tecnologias da Informação e Comunicação e formaç̧ão de professores: sobre rede e escolas. Educação e Sociedade, vol. 29, nº 104 - Especial, p. 747-768, out.2008.

AMARAL, S. F. do; BARROS, D. M.V...Estilos de aprendizagem no contexto educativo de uso das tecnologias digitais interativas. Disponível em:

http://www.lantec.fe.unicamp.br/lantec/pt/tvdi portugues/daniela.pdf $>$. Acesso em 04 de junho de 2016.

AMIEL, T; OREY, M.; WEST, R. Recursos Educacionais Abertos (REA): modelos para localização o adaptação. ETD - Educ. Tem. Dig, Campinas, v.12, n.esp., p.112-125, mar. 2011. Disponível em: $<$ https://www.fe.unicamp.br/revistas/ged/etd/article/view/2284>. Acessado em 04 de junho de 2016.

AREU, G. I. P.; FOFONCA, E.(orgs). Integração das tecnologias e da cultura digital na educação: múltiplos olhares. Curitiba: CRV, 2014

BALLÃO, C. Metodologia da pesquisa.Curitiba: IFPR, 2016.

BEARD, R. What is the role of the teacher today? Novembro, 2008. Disponível em: http://www.eppgroup.eu/press/peve08/docs/081113rogerbeard-lecture-en.pdf. Acesso em 28 maio 2016. 
COLL, Cesar; MONEREO, C. (org.). Psicologia da Educação Virtual. Aprender e Ensinar com as Tecnologias da Informação e Comunicação. Porto Alegre: Artmed, 2010.

DEMO, P. Habilidades do Século XXI. Boletim Técnico do SENAC: a Revista da Educação profissional. V.34, n.2, maio/agosto, SENAC Ed. Rio de Janeiro. 2008.

DEMO, Pedro. Aprendizagens e novas tecnologias. Rev. Bras. de Docência, Ensino e Pesquisa em Educação Física. Ago 2009, Vol. 1, n.1, p.53-75

FOFONCA, E. Entre o Processo Educativo e a Prática Comunicacional: o caso dos Blogs no Webjornalismo - Gazeta do Povo e O Globo Online. Dissertação de Mestrado. UTP: Curitiba, PR, 2010.

. Conexões entre Comunicação e Educação: novas sensibilidades e novos saberes. Razón y Palabra. N.76/maio. México, 2011.

. Comunicação e Educação: conexões em tempos de sociabilidade e convergência digital. O jornalismo e os blogs em sua dimensão educativa. Curitiba, PR: CRV, 2012.

. Entre as práticas de (multi)letramento e os processos de aprendizagem ubíqua da cultura digital: percepções estéticas de educadores das linguagens. Tese de doutorado, EAHC, São Paulo: Mackenzie, 2015.

KENSKI, V. M. Educação e tecnologias: O novo ritmo da informação. Campinas: Papirus, 2007.

Educação e tecnologias: o novo ritmo da informação. Campinas, SP: Papirus, 2012.

. Tecnologias e ensino presencial e a distância. 9. ed. Campinas: Papirus, 2012

KERCKHOVE, D. Inteligencias em conexion. Hacia una sociedad de la web. Madri: Gedisa, 1999.

MARCONI, M. de A.; LAKATOS, E. M. Técnicas de pesquisa: planejamento e execução de pesquisas, mostragens e técnicas de pesquisa, elaboração análise e interpretação de dados. 4. Ed. São Paulo: Atlas, 1999.

MORAIS, C. S. "Química digital" Recursos digitais no ensino da química: uma experiência no $7^{\circ}$ ano de escolaridade. Dissertação de Mestrado em Multimídia. Faculdade deCiências, Universidade do Porto.Maio/2006.

OESTERREICH, F.; MONTOLI, F. da S. Potencialidades e fragilidades das ferramentas tecnológicas em ambientes virtuais de aprendizagem. Revista Tecnologias na Educação, ano 2, n. 2, dez. 2010. Disponível em: <http://tecnologiasnaeducacao.pro.br/>.

VYGOTSKY, L. S. A Formação Social da Mente. São Paulo: Martins Fontes. 1984. 
WOODBRIDGE, J. Technology integration as a transforming teaching

strategy.2004.Disponível em: $<$ http://www.techlearning.com/article/2022>. Acesso em 15 ago. 2010.

\section{OS AUTORES}

Marilene Alves Ramos Dias é mestre e doutoranda em Produção Vegetal pela Universidade Federal do Tocantins. Bolsista pela Coordenação de Aperfeiçoamento de Pessoal de Nível Superior (CAPES).

E-mail: maridiasgpi@hotmail.com

Eduardo Fofonca é Doutor em Educação, Arte e História da Cultura pela Universidade Presbiteriana Mackenzie, SP. Pós-doutor em Educação pela Universidade do Estado de Santa Catarina. Instituto Federal do Paraná.

E-mail:eduardo.fofonca@ifpr.edu.br

Katia Andreá Silva da Costa é mestranda em Educação pela Universidade do Estado de Santa Catarina. Instituto Federal do Paraná. 